\title{
Afterword
}

\section{Towards a Future Paradigm}

Ross W. Prior, University of Wolverhampton, United Kingdom

\begin{abstract}
:
The use of art as research has greatly matured, and, despite the current preoccupation with measurement in the education sector, artistic research has continued to gain acceptance as a legitimate methodology for artists. Yet art-based research is still not completely and universally embedded within higher education learning and teaching approaches. The field's continued lack of confidence in using art as a vehicle of research is one reason. There is a need to stop relying upon other disciplines to justify the power of art. If we acknowledge that words cannot always reveal the uniquely felt qualities of art, then we cannot persist in using words as exclusive modes of research. Personal, embodied ways of knowing are of interest to researchers, and values the importance of knowledge that is incrementally gained through the act of doing and being. However, art is empirical—art and art processes are observable and can be entwined throughout the art-making process as a methodology of inquiry. Proposed here, as a future paradigm, is the threefold primacy of art in research, learning and teaching - positioning art as the topic, process and outcome of research. Significantly art as research recognizes art objects as full participants and uses art as its evidence.
\end{abstract}

Keywords: art-based research, art as research, knowing, artist-educator-researchers, exposition

I vividly recall the early debates when researchers felt the necessity to justify the validity of qualitative research. It seems almost unimaginable that researchers once faced a battle of legitimacy against the dominant scientific quantitative methodology. Yet we are currently facing a crisis of legitimacy in higher education where governments and agencies responsible for higher education are privileging the measuring of performance. Those of us who have been involved with education as long as I have find the reliance upon metrics to rank institutions and their "performance" to be a somewhat meaningless and distracting exercise. Further, the very processes that are meant to raise quality and standards actually run the very real risk of doing the reverse. As a consequence, we have seen issues of grade inflation, lowering entry requirements, manipulation of curriculum structure to suit data-returns timelines, and an increase in non-academic staff and vast hours spent on administration, which is clearly time taken away from the core educational function. These consequences have a negative effect, but the blind belief in measurement is astonishing. Maybe the battle over quantitative and qualitative research is not yet over. There is, it still seems, unease about things that refuse to be meaningfully measured. So it is within this context that this particular book raises the profile of a third research paradigm — artistic research. 
One definition of artistic research I can offer reinforces the contribution it makes both to the artist and to the field more broadly:

Art as research involves a diverse range of human activities in creating visual, auditory or performed artworks, expressing the artist's imaginative and/or technical skill, intended to be appreciated for their beauty or emotional impact. Art as research uses systematic investigation into the study of process, materials and sources in order to understand art more completely and reach new conclusions. The primary components in using art as research are documentation, discovery and interpretation for the purpose of the advancement of artistic knowledge and furthering understanding of all of life and other disciplines too. (Prior 2018b, 3)

How we embed "art as research" into the curriculum was the subject of my book Using Art as Research in Learning and Teaching (Prior 2018a). I have for some time felt uneasy that we only generally seemed to acknowledge artistic research at masters or doctoral levels when it could be embedded across all levels of higher education. But equally, I encounter many students who do not look to their own practice for a PhD study but feel that to undertake "real" research they must look outside of their own discipline. I have never fully understood why artists have felt so disempowered by research when they, by instinct, are generally good at doing it. However practice alone is not necessarily research, and how we frame what we do - that is, the intention - ultimately marks a research study. I have previously written that "as researchers we must find time and ways to stop, step back and reflect, particularly during artistic creation. This allows the reflective artist or artist-researcher to fully recognize what it is they know" (Prior 2013, 165), which is precisely why we can call it re-search.

Artists call upon multiple ways of knowing, which are likely to become further enhanced through the direct experience of practice. These complex understandings are entwined within the act of "doing and being" (Prior 2013, 164), and, because they can be thoroughly embodied, it can be difficult for the outsider to fully appreciate all that is involved with being an artist. Indeed, it can frequently be difficult for the artist to fully appreciate all that they know. Elliot Eisner identified this when he wrote that "knowledge is less a discovery than it is a construction" $(2002,211)$. It is clear that knowledge is constructed in and through practice (both noun and verb), which is not linear but is more acquired, or accumulated as a web of understanding over time. Experiential knowing for artists is derived through, for example, "accident, playfulness, repetition, improvisation, intuition, inspiration, emotional response and experience itself" (Prior 2018b, 8).

The "art-based research" (ABR) or the "art as research" movement offers us the illumination we require within artistic practice. It provides a confidence in the artist, the artistic process and even the non-verbal. As the father of ABR, Shaun McNiff has contributed monumentally to advancing our understanding of it. He advocates:

Art is a way of knowing, problem solving, healing and transformation that we marginalize if we do not embrace it as a vehicle of research. There is a striking 
disconnect when people and professions understanding the unique resources of the arts in addressing problems and issues inaccessible to verbal analysis nevertheless persist in the use of the latter as an exclusive foundation of research. (McNiff 2013, xiii)

I have previously pointed out that where we still have much work to do would have to be in "our continued lack of confidence in using art as that vehicle of research and the urgent need to stop relying upon other disciplines to justify the power of art" (Prior 2017, 265). I share this particular concern with McNiff, and we have both attempted over time to assist our respective and joint communities to develop both understanding and confidence. Developing art as research within learning and teaching was the reason I convened the first conference of art-based research in 2016 hosted by the University of Wolverhampton in the United Kingdom. It was at this conference that we determined that there was a lack of guidance for educators in how to better include artistic research into the higher education curriculum. McNiff $(2018, \mathrm{xi})$ in reporting on the conference noted that "the general sense from the three days of presentations and discussions was that concerns about legitimacy were the chief deterrents to the use of art as research." The delegates felt the weight of pressure of how artistic research was being (or not being) valued within our higher education institutions. Supportively, but realistically, McNiff (2015) reminds us that "the creative act involves doing things differently, sometimes even in unthinkable and illogical ways, which can be risky when the world values conformity and prescribed truths" (p. 2).

Whilst acknowledging that change within the sector will take time, the 2016 conference delegates were able to evidence an array of creative practices that affirmed the types of research they were doing were valuable to their own practice as artist-educator-researchers. Across a range of concerns and applied uses, art was being employed as a meaningful vehicle for discovery, be it for children with autism, actors with dyslexia, medical education, researchers using visual research methodologies, artists understanding their own creative practice, or more philosophically using art as a procedure of truth to explore the sensory, momentary and aesthetic nature of artistic expression. Arguably, the field requires more conferences of this type where a variety of artistic practices can share art-based research this way.

The journey of artistic enquiry of course begins many years before students enter higher education and that is why it is essential that we begin to infuse artistic research within creative processes at all levels of education in ways that are age-appropriate. It should then become an accepted methodology for understanding just as it is in the natural and the social sciences. However as I have said in the past, "this cycle of misunderstanding will not be completely broken until the higher education experience is renewed to entwine art as the methodology for inquiry throughout the entire art-making process" (Prior 2018c, 48-49, original emphasis). We need more graduates who understand and use art as research so that when they themselves teach or assist others in their learning they can helpfully support artistic research. Only in this way will artists truly resist what McNiff $(2018$, xiii) calls "the corporate academic research complex." 
There is still sector-wide ignorance surrounding how to deal with knowledge that is subjective and embodied. Misunderstandings generally result from a lack of clarity about the concept of research itself. Some of the tenets of research are undeniable - research is systematic, it investigates and searches for new knowledge. At its center, research seeks to answer (and discover) a specific question or set of questions. Rather than shoehorning a study into a particular methodological approach, selecting an appropriate methodology that is most useful to any question is essential. What we learn from research does not need to be quantified or qualified according to data sets. Art does not need additional "data" - the art is what we use. However, art is actually empirical — art as research can be based on, concerned with, or verified by observation or experience rather than theory or pure logic. Art and art processes are entirely observable and therefore undeniably researchable.

Whilst artists should not feel as though they need to constantly defend artistic research, it is essential they have a language to eloquently defend their approach and that is why books such as this are assisting our community. Artist-educator-researchers must adopt clear ways of discussing art as research and articulate the intrinsic value of specific, subjective and embodied knowledge. Artists must gain confidence in using art as the methodology that best suits their purpose. I have previously affirmed that "any form of research, be it experimental or not, must be sufficiently open to allow the indistinct to become apparent and sufficient space to facilitate the discovery of what is not yet known"' (Prior 2018b, 10). Art as research provides opportunities to answer questions that arise in and through practice.

However, as foreshadowed above, the artistic process also allows for doing research to find questions, not only to find answers. Mitchell Kossak $(2012,22)$ succinctly captures the essentially grounded nature of art as research:

Art-based research, a natural outgrowth of art-based enquiry, utilizes creative intelligence through immersion in creative process and scholarly reflection. [...] In artbased research, the phenomenological experience is represented through the creative act itself. The artwork, no matter what the medium (sound, rhythm, movement, enactment, poetry, paintings), opens up a space in which both the world and our being in the world is brought to light as a single, but inexhaustibly rich totality.

In teaching others to use artistic research I have found it important to shift the notion of proof, and this can only be done by fully recognizing the difference of creative work and fully appreciating the knowledge produced in and through practice. Our art, no matter the art form, provides the "proof." Art is the evidence - we must accept this if we truly believe in the aesthetic power of art. We know that art does what linguistic analysis alone cannot.

\section{Towards the Future}

The progress we make as artist-educator-researchers is happening now, and there is no essential need to make future predictions about how the world will view research going forward. However there is tremendous skepticism about facts, knowledge and authority 
derived from the "anything goes" world of Postmodernism and that is being replaced by an increasingly superficial participation in culture, evident in the shallowness of "post-

Postmodernity." However alongside a digital "click-bait" culture there is growing cultural idealism, tempering reason with faith, conviction and belief. What art-as-research allows is the openness and fluidity that the world is currently seeking in its rejection of singular prescribed truths and that offers a penetrating understanding to what we believe and feel. Art as research affirms the individual artist and their subjective knowing, and critically positions artists at the center of its research. Artistic research allows artists to come closer to knowing their own practice more fully. I have previously referred to this connection with the creative process:

As we use artistic processes in the creation of artefacts, ephemeral or permanent, collaboratively or alone, we engage in a complex act that is informed by the known and the unknown. We draw upon both conscious and tacit knowledge. Further, through the process of creation we generate new knowledge and the increased discovery of one's self and one's relationship to art. The completed artwork then becomes its own source for understanding, both for the artist and for the "recipient." (Prior 2018c, 47)

Studying artistic processes reveals a great deal of what can be called "depth-knowledge." Art-based inquiry, therefore, "includes multiple ways of knowing, including affective, sensory, creative, observational and intuitional, as well as the use of experimentation, risk taking, discovery and meaning making through art making" (Kossak 2012, 22). The possibilities for artist-educator-researchers offer considerable scope in the quest for understanding. Sequestering research activity during the learning and teaching process simply does not make sense. Research is integral to any artist's knowing and therefore needs to be explicitly addressed in the learning context, and creative inquiry placed center stage.

As a way forward, I offer a paradigm that could be used to more completely understand art as research. I call this the "threefold primacy of art in research, learning and teaching" (Prior 2018c, 57). Artistic research positions art as the topic, process and outcome of research.

Research in art can form the topic, the process and even be the outcome of research. If this concept becomes the mantra of what we do, then artist-educator-researchers will more fully understand the potential of art.

\section{Topic}

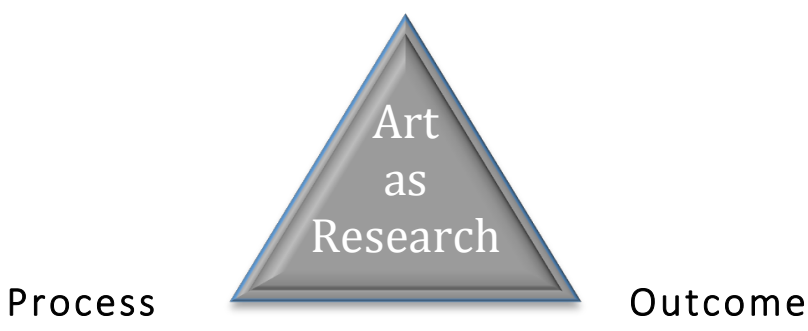


Figure 1. The threefold primacy of art in research, learning and teaching. Source: Prior 2018c.

It is the rich interplay between the artifact or the creative expression that provides the opportunity for deep investigation between artist and artwork. "In other words, in art-based research we can ask what the object or creative expression reveals about itself and what role the artist plays" (Prior 2018c, 56-57, original emphasis). Like McNiff, I do not see it as necessary to provide an accompanying narrative by the artist that runs the risk of giving a self-referential, one-sided emoted account of what the artist experienced or intended. The use of art-based research offers a more complete research approach that "recognizes objects as full participants" (McNiff 1998, 55), which is a most important distinction here. This notion is supported by Kathryn Church (2008: 433) who similarly makes a case for the artifact and the active interplay between the artwork, creative or expressive process and the artist as researcher:

[...] taking objects seriously, encountering them directly, proceeding object by object to unfold a study, tracking back and forth in the dialogic space between objects and their makers/users, and working reflexively with our limitations, confusions, and discoveries.

Within the higher education context this is precisely what we need to ensure that our students can do, and we too can be more embracing across art forms in doing so. In artbased research, it is highly acceptable to respond to artworks that one creates (or are created by others) through the use of other artistic media such as poetry, dance, performance, drawing and so on (Prior 2018c, 57). We must not deny the creative form in the use of expressive interpretations. Surely we must move away from privileging written (and sometimes stultifying) narratives of analysis? Helpfully McNiff $(1998,193)$ states, "If [...] words are incapable of revealing the unique qualities and spirits of art [...], why do we persist in using them as exclusive modes of research?" However, he would also agree that in order to more widely communicate research findings, it will most likely be inevitable in a research study that these will be written-up or verbally communicated in some form or other, but this should not be the sole the mode of inquiry.

Therefore, through systematic inquiry, art-based research seeks to find answers to artistic phenomena. Essentially, this type of research must connect to practices within the discipline if it is to be of use to others. Its true value may reside in the depth of observation and value one may give to an object or performance. The development of a creative relationship with an artwork offers students the opportunity of learning something new from both their creative or expressive process and their own artwork. This can be an embedded part of learning within artistic practice. Delightfully, perhaps, the outcome of artistic enquiry is unpredictable because meaning is created in and through the expressive process. This unpredictability should be uniquely celebrated and not marginalized by the language of the sciences. Artistic research is open to subjective, random, specific and non-generalizable 
findings. Jacqueline Taylor $(2018,97)$ resolves that "art-based research is underpinned by a tension between producing research that is robust, rigorous and valid, and yet at the same time retains its very qualities as a site of possibility."

Within visual art in particular, for doctoral students in presenting submissions, colleagues (Gray et al. 2018) have had great success in the use of "exposition" as a means of revealing the process of inquiry. In fact expositions offer all art forms, including interdisciplinary art forms, approaches to presenting art as research. Rather than the usual exhibition of finished or resolved work, the exposition has a more educative function; it can reveal thinking and methodology, and "perhaps most importantly it invites participation in order to enrich and expand understandings from the inquiry" (Gray et al. 2018, 116).

The context in which an exposition is located is an important consideration. Gray et al. $(2018,122)$ make these specific and useful recommendations:

However, the exposition is not an exhibition and the researcher must make this distinction, and provide criteria by which the materials displayed can be understood and evaluated. An abstract, key words, and a glossary of terms will help to quickly orient examiners (and public) to the focus and parameters of the inquiry. There may be a number of means by which the creative inquiry can be contextualised in terms of key thinking and practice in the defined field. For example, a mapping of the context of inquiry, key quotes, key references. Increasingly the use of social media tools as a means of sharing and testing ideas about the questions and assumptions of an inquiry is a valuable feedback mechanism, as well as providing on-going contemporary contextualisation.

Unfortunately many of the attempts to use exposition have not resulted in their being captured for future reference. It is therefore crucial that expositions are somehow recorded and documented for posterity in order to share them across our artistic community of practice and for researchers at all levels. Digital platforms offer one solution in capturing the completeness of artistic work. To these ends, digital technology may more broadly provide artists with the tools of capturing processes for further investigation. Many people recognize the rich possibilities of new media, yet are "frustrated by the lack of progress within academia to develop this as legitimate artistic research, still continuing to largely privilege the written word or reliance upon other methodologies that are not so pertinent to artistic practice" (Prior 2018c, 51).

\section{Conclusion}

In providing this Afterword, it has not been my intention to summarize the many illuminating contributions in this book, but rather to tie some threads together and help us move forward in the field with greater confidence. Indeed, confidence seems to be key to any progress. For artists, "using art as research brings together the known and the unknown, the planned and the unplanned, the seen and unseen, the incidental and accidental, all in the creation of new knowledge" (Prior 2018c, 58). In particular this offers exciting potential 
for learning possibilities within artistic higher education. To these ends, Kathryn Church

$(2008,433)$ asks:

Will we value the "accidental" quality of the journey that they open up for us? Can we lose control over how we come into knowing? Or will we turn creative inquiry into familiar order: a step-wise and predictable set of practices, planned and tidy, learned as part of a formal curriculum?

Within higher education learning and teaching we are well positioned to ensure that art can be the topic, process and outcome of research. At its heart, knowledge construction through artistic practice provides a meaningful way forward for the field. Through embracing the accidental, haptic and frequently messy, artists can be entirely confident in using nonscientific research methodologies.

Put simply; art provides the evidence of what we do.

\section{References}

Church, Kathryn. 2008. "Exhibiting as Inquiry: Travels of an Accidental Curator." In Handbook of the Arts in Qualitative Research: Perspectives, Methodologies, Examples, and Issues, edited by J. Gary Knowles and Ardra L. Cole, 421-434. Los Angeles: Sage.

Eisner, Elliot W. 2002. The Arts and the Creation of Mind, New Haven: Yale University Press.

Gray, Carole, Malins, Julian and Bristow, Maxine. 2018. "The 'epistemic object' in the creative process of doctoral inquiry." In Using Art as Research in Learning and Teaching, edited by Ross W. Prior, 109-125. Bristol: Intellect/University of Chicago Press.

Kossak, Mitchell. 2012. "Art-based enquiry: It is what we do!" Journal of Applied Arts and Health, 3:1, 21-29.

McNiff, Shaun. 1998. Art-Based Research, London: Jessica Kingsley.

McNiff, Shaun, ed. 2013. Art as Research: Opportunities and Challenges, Bristol: Intellect.

2015. Imagination in Action: secrets for unleashing creative expression,

Boston, MA: Shambhala.

McNiff, Shaun. 2018. "Foreword." In Using Art as Research in Learning and Teaching: Multidisciplinary Approaches Across The Arts, edited by Ross W. Prior, xi-xv. Bristol: Intellect/University of Chicago Press.

Prior, Ross W. 2012. Teaching Actors: Knowledge Transfer in Actor Training, Bristol: Intellect/University of Chicago Press. 
2013. "Knowing what is known: accessing craft-based meanings in research by artists." In Art as Research: Opportunities and Challenges, edited by Shaun McNiff, 161-169. Bristol: Intellect/The University of Chicago Press.

2017. "Afterword: Confidence in Art as Evidence." In Applied Practice: Evidence and Impact in Theatre, Music and Art, edited by Nick Rowe and Matthew Reason, 262-267. London: Bloomsbury Methuen.

ed. 2018a. Using Art as Research in Learning and Teaching: Multidisciplinary Approaches Across The Arts, Bristol: Intellect/University of Chicago Press.

2018b. "Introduction: Artist-educator-researcher." In Using Art as Research in Learning and Teaching, edited by Ross W. Prior, 2-12. Bristol: Intellect/University of Chicago Press.

2018c. "Art as the topic, process and outcome of research within higher education." In Using Art as Research In Learning and Teaching, edited by Ross W. Prior, 4260. Bristol: Intellect/University of Chicago Press.

Taylor, Jacqueline. 2018. "Research-Practice-Pedagogy: Establishing New Topologies of Doctoral research in the Arts." In Using Art as Research in Learning and Teaching, edited by Ross W. Prior, 90-108. Bristol: Intellect/University of Chicago Press.

\section{Biography}

Ross W. Prior

is Professor of Learning and Teaching in the Arts in Higher Education at the University of Wolverhampton, United Kingdom. In addition to his books Teaching Actors: Knowledge Transfer in Actor Training and Using Art as Research in Learning and Teaching, he is the founding principal editor of the Journal of Applied Arts and Health, established in 2010. Professor Prior is a member of the Arts \& Humanities Research Council (AHRC) Peer Review College, Fellow of the Royal Society for Public Health and Principal Fellow of the Higher Education Academy. 